\title{
CoP as an Acid-Stable Active Electrocatalyst for the Hydrogen- Evolution Reaction: Electrochemical Synthesis, Interfacial Characterization and Performance Evaluation
}

Fadl H. Saadi, ${ }^{\dagger, \ddagger}$ Azhar I. Carim, ${ }^{\ddagger}$ Erik Verlage $^{\dagger, \ddagger}$ John C. Hemminger, ${ }^{\ddagger}, \#$ Nathan S. Lewis, ${ }^{*}, \ddagger, \S, \|, \perp$ and Manuel P. Soriaga $*,+, \nabla$

${ }^{\dagger}$ Division of Engineering and Applied Sciences, ${ }^{\ddagger}$ Joint Center for Artificial Photosynthesis, ${ }^{\S}$ Division of Chemistry and Chemical Engineering, "Beckman Institute, and ${ }^{\perp}$ Kavli Nanoscience Institute, California Institute of Technology, Pasadena, California 91125, United States

\# Department of Chemistry, University of California, Irvine, California 92697, United States

${ }^{\nabla}$ Department of Chemistry, Texas A\&M University, College Station, Texas 77843, United States

Supporting Information

ABSTRACT: Films of CoP have been electrochemically synthesized, characterized, and evaluated for performance as a catalyst for the hydrogen-evolution reaction (HER). The film was synthesized by cathodic deposition from a boric acid solution of $\mathrm{Co}^{2+}$ and $\mathrm{H}_{2} \mathrm{PO}_{2}^{-}$on copper substrates followed by operando remediation of exogenous contaminants. The films were characterized structurally and compositionally by scanning-electron microscopy, energy-dispersive X-ray spectroscopy, X-ray photoelectron spectroscopy, and Raman spectrophotometry. The catalytic activity was evaluated by cyclic voltammetry and chronopotentiometry. Surface characterization prior to electrocatalysis indicated that the film consisted of micrometer-sized spherical clusters located randomly and loosely on a slightly roughened surface. The composition of both the clusters and surface consisted of cobalt in the metallic, phosphide, and amorphous-oxide forms ( $\mathrm{CoO}$. $\mathrm{Co}_{2} \mathrm{O}_{3}$ ) and of phosphorus as phosphide and orthophosphate. The orthophos-

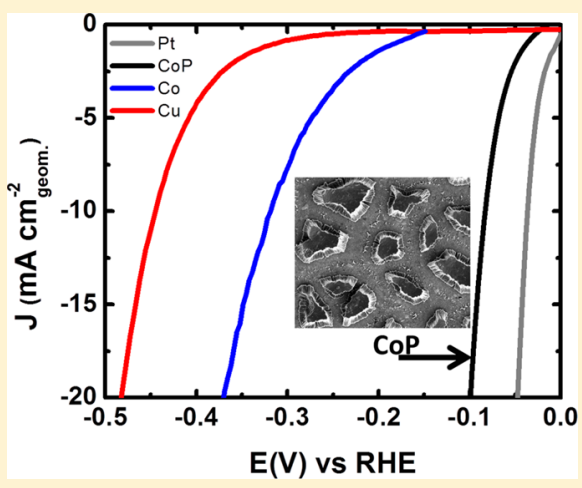
phate species, produced by air-oxidation, were eliminated upon HER electrocatalysis in sulfuric acid. The operando film purification yielded a functional electrocatalyst with a Co:P stoichiometric ratio of 1:1. After the HER, the surface was densely packed with micrometer-sized, mesa-like particles whose tops were flat and smooth. The CoP eletrodeposit exhibited an $85 \mathrm{mV}$ overvoltage $(\eta)$ for the HER at a current density of $10 \mathrm{~mA} \mathrm{~cm}$ and was stable under operation in highly acidic solution, with an increase in $\eta$ of $18 \mathrm{mV}$ after $24 \mathrm{~h}$ of continuous operation. The comparative HER catalytic performance of CoP, film or nanoparticles, is as follows: $\eta_{\mathrm{Pt}}<\eta_{\mathrm{CoP} \text { film }}=\eta_{\mathrm{CoP} \mathrm{NP}}, \eta_{\mathrm{Ni}_{2} \mathrm{P}}<\eta_{\mathrm{CoSe}_{2}}<\eta_{\mathrm{MoS}_{2}}<\eta_{\mathrm{MoSe}_{2}}$.

\section{INTRODUCTION}

The development of renewable-energy technologies, ${ }^{1-4}$ such as photovoltaic-driven water electrolysis and artificial photosynthesis, is hindered because one of its pivotal reactions, the electrochemical decomposition of water to $\mathrm{H}_{2}(g)$ and $\mathrm{O}_{2}(g)$, is electrochemically sluggish at most non-noble-metal electrodes. The viability of this approach depends upon (i) light-capturing semiconducting electrodes to overcome the thermodynamic obstacles and efficiently generate, from sunlight, sufficient electromotive force to drive the reaction, and (ii) highly active electrocatalysts, desirably comprised of earth-abundant materials, to circumvent the activation barrier via less tortuous mechanistic paths for the anodic (oxygen-evolution) and the cathodic (hydrogen-evolution) half-reactions.

Platinum presently is the most active electrocatalyst for the hydrogen-evolution reaction (HER) regardless of the acidity or alkalinity of the medium. ${ }^{4-7}$ However, $\mathrm{Pt}$ is scarce and expensive, and thus is problematic to consider for energy- conversion applications at a global scale. Additionally, relatively few active HER catalysts are stable under highly acidic reaction conditions.

The acid-stable, earth-abundant HER catalysts reported in the literature share a commonality in that they consist of at least one Group VI transition metal and one chalcogenide. Specific examples are molybdenum sulfide, ${ }^{6,8-11}$ tungsten sulfide, ${ }^{11}$ molybdenum selenide, ${ }^{12}$ tungsten selenide, ${ }^{13}$ cobalt selenide, ${ }^{14}$ and molybdenum carbide. ${ }^{15}$ Crystalline nanoparticles of $\mathrm{Ni}_{2} \mathrm{P}, \mathrm{MoP}$, and $\mathrm{CoP}$ have also been reported as acid-compatible HER catalysts that exhibit low overpotentials in acidic electrolytes. ${ }^{16-21}$ Additionally, $\mathrm{Ni}-\mathrm{P}$ and $\mathrm{Co}-\mathrm{P}$ alloys have been studied as alkaline-stable HER catalysts, although the

Special Issue: John C. Hemminger Festschrift

Received: June 2, 2014

Revised: $\quad$ September 27, 2014

Published: September 27, 2014 

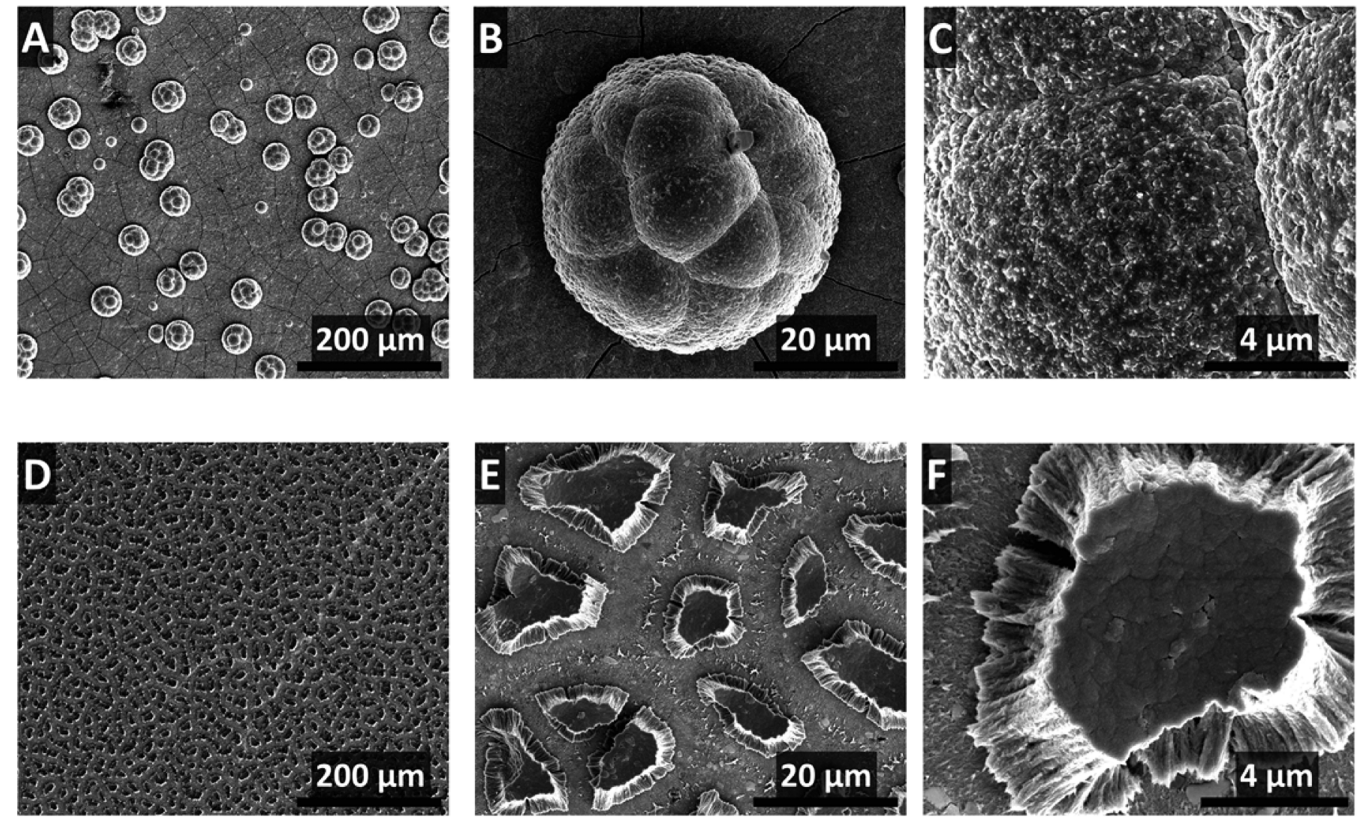

Figure 1. Scanning-electron micrographs of the films before $(A-C)$ and after $(D-F)$ voltammetry. (A) An as-deposited thin film showed the presence of quasi-spherical clusters on the surface. (B and C) The film underneath the particles appeared uniformly roughened. (D) Postelectrolysis film showed close-packed plateau-topped islands on the surface. (E and F) The tops of the mesa-like islands were flat and relatively smooth.

exact compositions and activities were irreproducible among different samples. ${ }^{22-26}$ We describe herein a facile electrochemical method for the synthesis of a cobalt phosphide film that displays high HER activity and significant operando acid stability.

\section{EXPERIMENTAL SECTION}

All chemical reagents were analytical grade and used without further purification. Ultraclean water with resistivity higher than 18.2 $\mathrm{M} \Omega \mathrm{cm}$ was generated from a Barnstead Nanopure system (Thermo Scientific, Asheville, NC, USA). Unless otherwise specified, all experiments were performed under ambient laboratory conditions.

Rotating-Disk Electrode Substrates. Copper disks (Alfa Aesar, Ward Hill, MA, USA) that were used as deposition substrates were $5 \mathrm{~mm}$ diameter, $4 \mathrm{~mm}$ thickness, and $99.999 \%$ purity. The disks were metallographically burnished on a LaboPol-5 polisher (Struers Inc., Cleveland, OH, USA), initially with $15 \mu \mathrm{m} \mathrm{SiC} \mathrm{(Buehler,} \mathrm{Lake} \mathrm{Bluff,} \mathrm{IL,} \mathrm{USA)} \mathrm{and}$ subsequently with progressively decreased grit size $(9,6,3$, to $1 \mu \mathrm{m}$ ) diamond paste. The disks were then cleaned with a 0.06 $\mu \mathrm{m}$ colloidal suspension of silica and sonicated for $5 \mathrm{~min}$ in Nanopure water.

Electrochemistry. Electrochemical experiments were performed in a $150 \mathrm{~mL}$ five-port glass cell that was equipped with a 99\% pure graphite rod (Alfa Aesar) that served as a counter electrode and a saturated calomel electrode (SCE; $\mathrm{CH}$ Instruments, Austin, TX, USA) as reference. The SCE was calibrated $(266 \mathrm{mV})$ against a reversible hydrogen electrode (RHE) in $0.5 \mathrm{M} \mathrm{H}_{2} \mathrm{SO}_{4}$. Potential control was accomplished with a BioLogic SP-200 potentiostat (Biologic, Grenoble, France). The uncompensated cell resistance was determined from a single-point high-frequency impedance measurement and was compensated ( $85 \%$ ) by the built-in positive-feedback software.

The cobalt phosphide film was electrodeposited onto a $\mathrm{Cu}$ disk from a $250 \mathrm{~mL}$ solution that consisted of $0.928 \mathrm{~g}(0.15 \mathrm{M})$ of boric acid, $\mathrm{H}_{3} \mathrm{BO}_{3}$ (Alfa Aesar), $0.584 \mathrm{~g}$ of $(0.10 \mathrm{M})$ sodium chloride, $\mathrm{NaCl}$ (Macron Fine Chemicals, Center Valley, PA, USA), $3.48 \mathrm{~g}$ of $(0.30 \mathrm{M})$ sodium hypophosphite, $\mathrm{NaPO}_{2} \mathrm{H}_{2}$ (Alfa Aesar), and $4.759 \mathrm{~g}$ of $(0.2 \mathrm{M})$ cobalt chloride, $\mathrm{CoCl}_{2}$ (Alfa Aesar). The $\mathrm{pH}$ of the solution, prior to and after the electrodeposition experiments, was 5.0. The rotating-disk electrode (RDE) was rotated at a frequency of $6.67 \mathrm{~Hz}(400$ $\mathrm{rpm}$ ) with the potential maintained at $-1.2 \mathrm{~V}$ vs SCE for 15 min. For control experiments, a cobalt-only film was prepared based on the same procedure but in the absence of $\mathrm{NaPO}_{2} \mathrm{H}_{2}$.

Hydrogen-evolution catalysis measurements were performed in a $0.50 \mathrm{M} \mathrm{H}_{2} \mathrm{SO}_{4}$ solution that was prepared from $18 \mathrm{M}$ $\mathrm{H}_{2} \mathrm{SO}_{4}$ (Sigma-Aldrich, St. Louis, MO, USA) by use of ultrapure water. In the HER experiments, the solution and the RDE cell were saturated with $99.999 \% \mathrm{H}_{2}(\mathrm{~g})$ (Air Liquide, Plumsteadville, PA, USA), and the RDE was rotated at 26.67 $\mathrm{Hz}(1600 \mathrm{rpm})$. Voltammetric data were obtained by cycling the potential between 0.0 and $-0.14 \mathrm{~V}$ vs RHE at a scan rate of $1 \mathrm{mV} \mathrm{s}^{-1}$. The operando stability of the films was evaluated by continuous cyclic voltammetry over a $24 \mathrm{~h}$ period. Chronopotentiometry at constant current density of $10 \mathrm{~mA}$ $\mathrm{cm}^{-2}$ was also performed during which the potential of the cobalt phosphide film was monitored over a $24 \mathrm{~h}$ period.

Interfacial Characterization. Scanning-electron micrographs were obtained using a Nova NanoSEM 450 microscope (FEI, Hillsboro, OR, USA) with an accelerating voltage of 15 $\mathrm{kV}$ and a working distance of $5.0 \mathrm{~mm}$. Low-magnification micrographs ( $>10 \mathrm{~nm} /$ pixel) were acquired with an EverhartThornley detector whereas higher magnification micrographs were obtained with a through-the-lens detector. Energydispersive X-ray spectra (EDS) were collected in the scanning-electron micrographs (SEMs) at an accelerating voltage of $15 \mathrm{kV}$ using a silicon drift detector (Oxford Instruments, Abingdon, United Kingdom). Inca software (Oxford Instruments) was used to interpret the EDS spectra.

X-ray photoelectron spectroscopy (XPS) data were obtained using an AXIS Ultra DLD instrument (Kratos Analytical, 
Manchester, U.K.) at a background pressure of $1 \times 10^{-9}$ Torr. High-intensity excitation was provided by monochromatic $\mathrm{Al}$ $\mathrm{K} \alpha \mathrm{X}$-rays, $1486.6 \mathrm{eV}$ in energy and $0.2 \mathrm{eV}$ resolution at full width at half-maximum. Photoelectrons were collected at $0^{\circ}$ from the surface normal at a retarding (pass) energy of $80 \mathrm{eV}$ for the survey scans, whereas a pass energy of $20 \mathrm{eV}$ was used for the high-resolution scans. The peak energies were calibrated against the binding energy $E_{\mathrm{B}}$ of the adventitious $C$ 1s peak. For quantitative analysis, the XPS peaks were fitted using CasaXPS software (CASA Ltd., Teignmouth, United Kingdom) to symmetric Voigt line shapes composed of Gaussian (70\%) and Lorentzian (30\%) functions that employed a Shirley background. $^{27}$ For both the Co and $\mathrm{P}$ peaks, the fitting was constrained to maintain a $2: 1$ ratio between the areas of the $2 \mathrm{p}_{3 / 2}$ and $2 \mathrm{p}_{1 / 2}$ peaks, with $E_{\mathrm{B}}$ separations of 0.85 and $15 \mathrm{eV}$ for $\mathrm{P}$ and Co, respectively. The atomic or molar ratio between $\mathrm{Co}$ and $\mathrm{P}$ was obtained from eq 1 :

$$
\frac{N_{\mathrm{Co}}}{N_{\mathrm{P}}}=\frac{A_{\mathrm{Co}} / S_{\mathrm{Co}}}{A_{\mathrm{P}} / S_{\mathrm{P}}}
$$

where $N$ is the number of atoms, $A$ is the total area of the photoemission peaks, and $S$ is the sensitivity factor. Values for $S$ ( 0.486 for $\mathrm{P}$ and 3.59 for $\mathrm{Co}$ ) were provided by the instrument manufacturer.

Raman spectra of the films were obtained with a Renishaw inVia Raman microprobe (Renishaw, Wotton Under Edge, United Kingdom) equipped with a Leica DM 2500 M microscope (Leica Microsystems, Buffalo Grove, IL, USA), a Leica N Plan 50× objective (numerical aperture $=0.75$ ), a 1800 lines $\mathrm{mm}^{-1}$ grating, and a CCD detector configured in a $180^{\circ}$ backscatter geometry. A $532 \mathrm{~nm}$ diode-pumped solid-state laser (Renishaw RL532C50) was used as the excitation and a $20 \mu \mathrm{W}$ radiant flux was incident onto the surface of the sample.

\section{RESULTS}

Characterization of Films Prior to Electrocatalysis. Scanning-electron micrographs of the as-deposited thin film (Figure 1A-C) showed the surfaces to be relatively smooth but with micrometer-sized spherical clusters randomly and loosely distributed throughout. Energy-dispersive X-ray spectroscopy indicated that the surface was composed primarily of cobalt and a minor amount of phosphorus in a Co:P ratio of 20:1 (Figure 2). EDS also yielded the same 20:1 ratio for the clusters.

Parts $\mathrm{A}$ and $\mathrm{B}$ of Figure 3 show high-resolution X-ray photoelectron spectra of the samples in the Co and $\mathrm{P}$ regions, respectively. The peaks at 778 and $793 \mathrm{eV}$ in Figure 3A correspond to the $2 \mathrm{p}_{3 / 2}$ and $2 \mathrm{p}_{1 / 2}$ peaks of zerovalent Co. All of the other peaks are associated with oxidized cobalt, $\mathrm{Co}_{3} \mathrm{O}_{4}$ $\left(\mathrm{CoO} \cdot \mathrm{Co}_{2} \mathrm{O}_{3}\right){ }^{28-31}$ The large peak in Figure $3 \mathrm{~B}$ at $133 \mathrm{eV}$ is assigned to orthophosphate, probably as the cobalt salt $\mathrm{Co}_{3}\left(\mathrm{PO}_{4}\right)_{2} \cdot{ }^{32,33}$ The observed broadening is consistent with an unresolved overlap of the $2 \mathrm{p}_{3 / 2}$ and $2 \mathrm{p}_{1 / 2}$ states. ${ }^{34}$ Based on eq 1 , the Co:P atomic ratio was determined to be $8: 1$. The latter is considerably smaller than the EDS-determined ratio (20:1) because X-rays emanate deeper from the sample bulk compared to photoemitted electrons. This difference in the Co:P ratio implies surface segregation of phosphorus in the asprepared sample.

The Raman spectrum of the as-deposited cobalt phosphide film (Figure 4) exhibited a broad, asymmetric band centered at $590 \mathrm{~cm}^{-1}$ which is characteristic of amorphous cobalt oxide. ${ }^{35}$ The shoulders at 487,522 , and $690 \mathrm{~cm}^{-1}$ are consistently

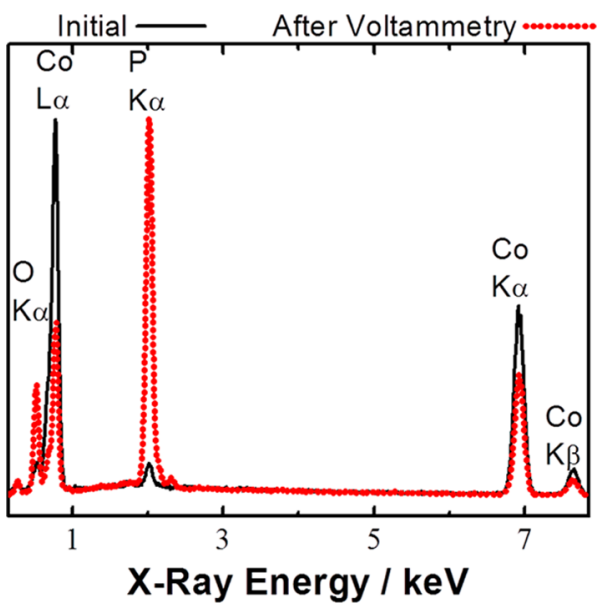

Figure 2. Energy-dispersive X-ray spectroscopy of the films before and after voltammetry. The Co:P atomic ratio decreased from 20:1 to 1:1 after the voltammetric experiments.

assigned to $\mathrm{Co}_{3} \mathrm{O}_{4}$ stretching modes $\left(\mathrm{E}_{\mathrm{g}}, \mathrm{F}_{2 \mathrm{~g}}\right.$, and $\left.\mathrm{A}_{1 \mathrm{~g}}\right){ }^{36}$ Additional peaks at 925, 981, and $1067 \mathrm{~cm}^{-1}$ were also observed and are consistent with $\mathrm{P}-\mathrm{O}$ stretching modes $\left(\nu_{1}\right.$ symmetric, $\nu_{1}$ symmetric, and $\nu_{3}$ antisymmetric, respectively). ${ }^{37,38}$

Electrochemistry. Figure 5 displays the cyclic current vs potential data for the cobalt phosphide thin film in aqueous $0.50 \mathrm{M} \mathrm{H}_{2} \mathrm{SO}_{4}$. In the first scan (Figure $5 \mathrm{~A}$ ), initially from the open-circuit potential $(-0.075 \mathrm{~V})$ to $0.025 \mathrm{~V}$ vs RHE, a large anodic current was observed that was not replicated in subsequent runs. After that first cycle, in all experiments, the overpotential $(\eta)$ needed to drive $10 \mathrm{~mA} \mathrm{~cm}{ }^{-2}$ of cathodic current was $85 \mathrm{mV}$ (RHE). This overpotential was significantly lower than those observed for the $\mathrm{Co}-\mathrm{on}-\mathrm{Cu}$ and pure- $\mathrm{Cu}$ control experiments (Figure 5B). Figure 5C shows a representative steady-state Tafel plot for the cobalt-phosphide

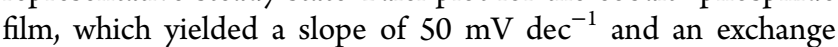
current density of $0.2 \mathrm{~mA} \mathrm{~cm}{ }^{-2}$. Figure 5D compares the Tafel plot of the subject compound with those of other HER catalysts. Only Pt outperformed the electrodeposited cobaltphosphide film under the stated test conditions.

Two methods were implemented to assess the operando stability of the catalytically active film in highly acidic environments. In one, the sample was cycled, uninterrupted, between 0.0 and $-0.14 \mathrm{~V}$ vs RHE in $0.5 \mathrm{M} \mathrm{H}_{2} \mathrm{SO}_{4}$ for $24 \mathrm{~h}$ and the ensuing cyclic voltammogram (CV) was compared with that for first cycle (Figure 6A). The $\mathrm{CV}$ data indicated an increase in $\eta$ from 85 to $100 \mathrm{mV}$ after the day-long test. The other stability-assessment method was based on chronopotentiometry, in which a constant current density of $10 \mathrm{~mA} \mathrm{~cm}{ }^{-2}$ was delivered over $24 \mathrm{~h}$ while the electrode potential, i.e., the value of $\eta$, was monitored (Figure 6B). The average increase in $\eta$ from the two methods was $17.5 \pm 4.5 \mathrm{mV}$.

Postelectrochemistry Film Characterization. Parts D-F of Figure 1 show SEM images of the film obtained after the HER catalysis experiments. The most notable difference between these images and the preelectrochemistry images of Figure $1 \mathrm{~A}-\mathrm{C}$ is that the film surface was no longer marred with loosely distributed quasi-spheres but was instead covered with close-packed plateau-topped particles that resembled micrometer-sized mesas. The tops of the mesa-like particles were relatively flat and smooth. Postelectrochemistry EDS measure- 
Cobalt XPS

A

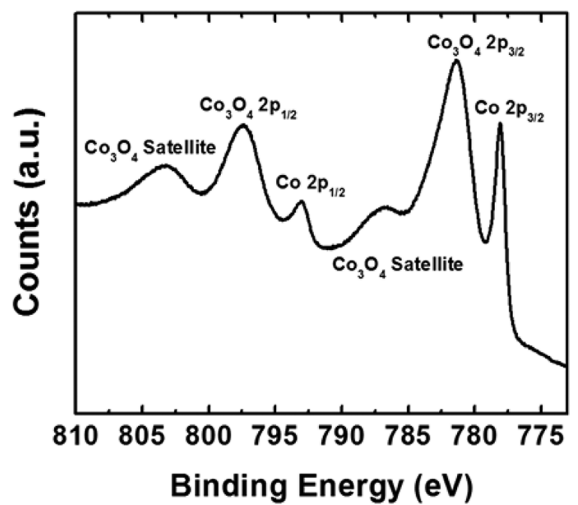

C

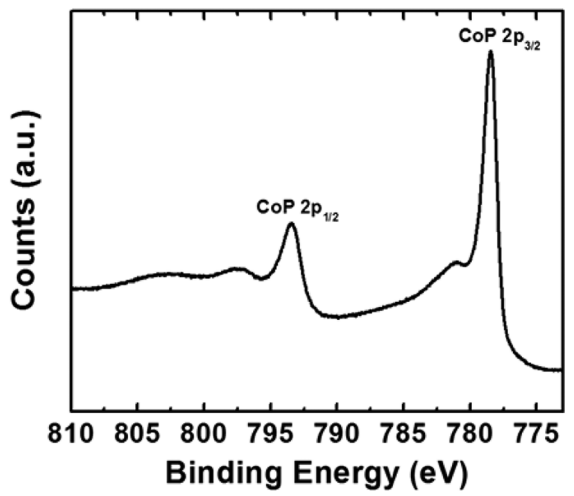

Phosphorous XPS

B

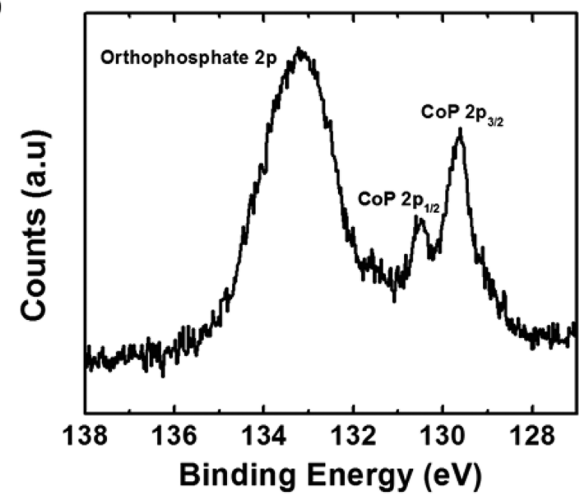

D

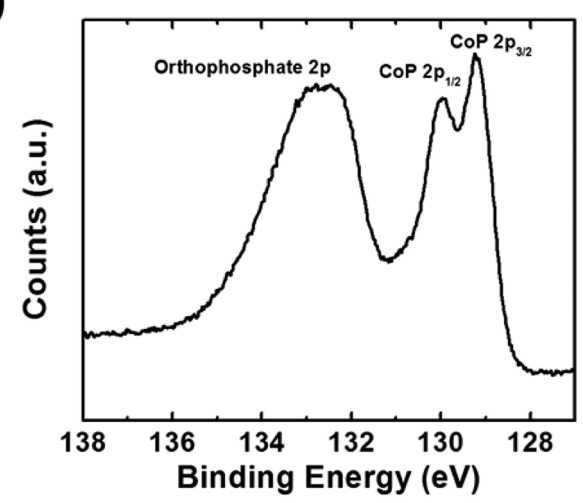

Figure 3. High-resolution X-ray photoelectron spectra of the (A) Co $2 p$ region of the as-deposited thin film, (B) P $2 p$ region of the as-deposited thin film, (C) Co $2 p$ region after voltammetry and (D) P $2 p$ region after voltammetry.

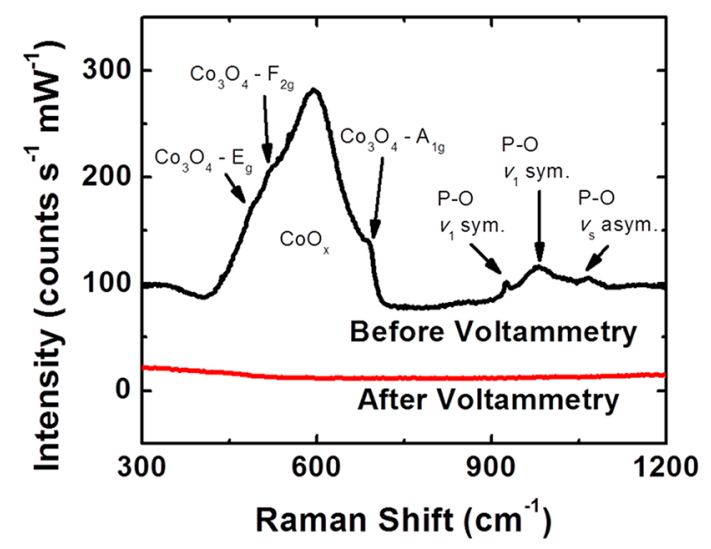

Figure 4. Raman spectra before and after voltammetry. The peaks at ca. $600 \mathrm{~cm}^{-1}$ correspond to $\mathrm{Co}-\mathrm{O}$ vibrational modes, whereas those at ca. $1100 \mathrm{~cm}^{-1}$ are attributable to $\mathrm{P}-\mathrm{O}$ modes.

ments (Figure 2) indicated that the Co:P ratio in the film decreased 20-fold, to 1:1.

Parts C and D of Figure 3 respectively show high-resolution XPS spectra of the sample in the $\mathrm{Co}$ and $\mathrm{P}$ regions. Comparison of Figure 3C with Figure 3A clearly indicates that all peaks attributable to cobalt oxides have diminished; the two major peaks represent Co $2 \mathrm{p} 3 / 2$ and Co $2 \mathrm{p} 1 / 2$ states in the stoichiometric CoP. ${ }^{21,32,39}$ Close inspection of Figure 3B,D reveals that the relative intensities of the postelectrochemistry phosphide peaks at 129 and $131 \mathrm{eV}$ increased, whereas that of the phosphate peak at $133 \mathrm{eV}$ decreased significantly. Based on eq 1 , the atomic ratio of cobalt and phosphorus after the hydrogen-evolution experiments decreased from $8: 1$ to $1: 1$, in agreement with the EDS results.

The Raman spectrum (Figure 4) after electrochemistry showed the absence of peaks at $600 \mathrm{~cm}^{-1}$, thus providing clear evidence that the catalytically active film did not contain cobalt oxide.

\section{DISCUSSION}

When a clean copper disk electrode is immersed in an aqueous solution of $0.15 \mathrm{M} \mathrm{H}_{3} \mathrm{BO}_{3}, 0.10 \mathrm{M} \mathrm{NaCl}, 0.30 \mathrm{M} \mathrm{NaPO}_{2} \mathrm{H}_{2}$, and $0.2 \mathrm{M} \mathrm{CoCl}_{2}$ and applied with a potential of $-1.2 \mathrm{~V}$, the following deposition reactions are expected to occur: ${ }^{40}$

$$
\begin{aligned}
& \mathrm{Co}^{2+}+2 e^{-} \rightarrow \mathrm{Co} \quad E^{\circ}=-0.28 \mathrm{~V} \\
& \mathrm{H}_{2} \mathrm{PO}_{2}^{-}+2 \mathrm{H}^{+}+e^{-} \rightarrow \mathrm{P}+2 \mathrm{H}_{2} \mathrm{O} \quad E^{\circ}=-0.248 \mathrm{~V}
\end{aligned}
$$

Spontaneous Co-P compound formation then occurs to give the net reaction:

$$
\begin{aligned}
& \mathrm{Co}^{2+}+\mathrm{H}_{2} \mathrm{PO}_{2}^{-}+2 \mathrm{H}^{+}+3 e^{-} \rightarrow \mathrm{CoP}+2 \mathrm{H}_{2} \mathrm{O} \\
& E^{\circ} \approx-0.28 \mathrm{~V}
\end{aligned}
$$

While a few stoichiometric compositions of cobalt phosphide are known (e.g., $\mathrm{Co}_{3} \mathrm{P}$ and $\mathrm{Co}_{2} \mathrm{P}$ ), ${ }^{25,32}$ the $\mathrm{CoP}$ formulation shown in eq 4 is based upon the postelectrocatalysis XPS and EDS results. The as-deposited film, whether examined by EDS, XPS, or Raman spectroscopy, showed a preponderance of higher valent $\mathrm{Co}$ and $\mathrm{P}$ species such as $\mathrm{Co}_{2} \mathrm{O}_{3}, \mathrm{CoO}$, and 

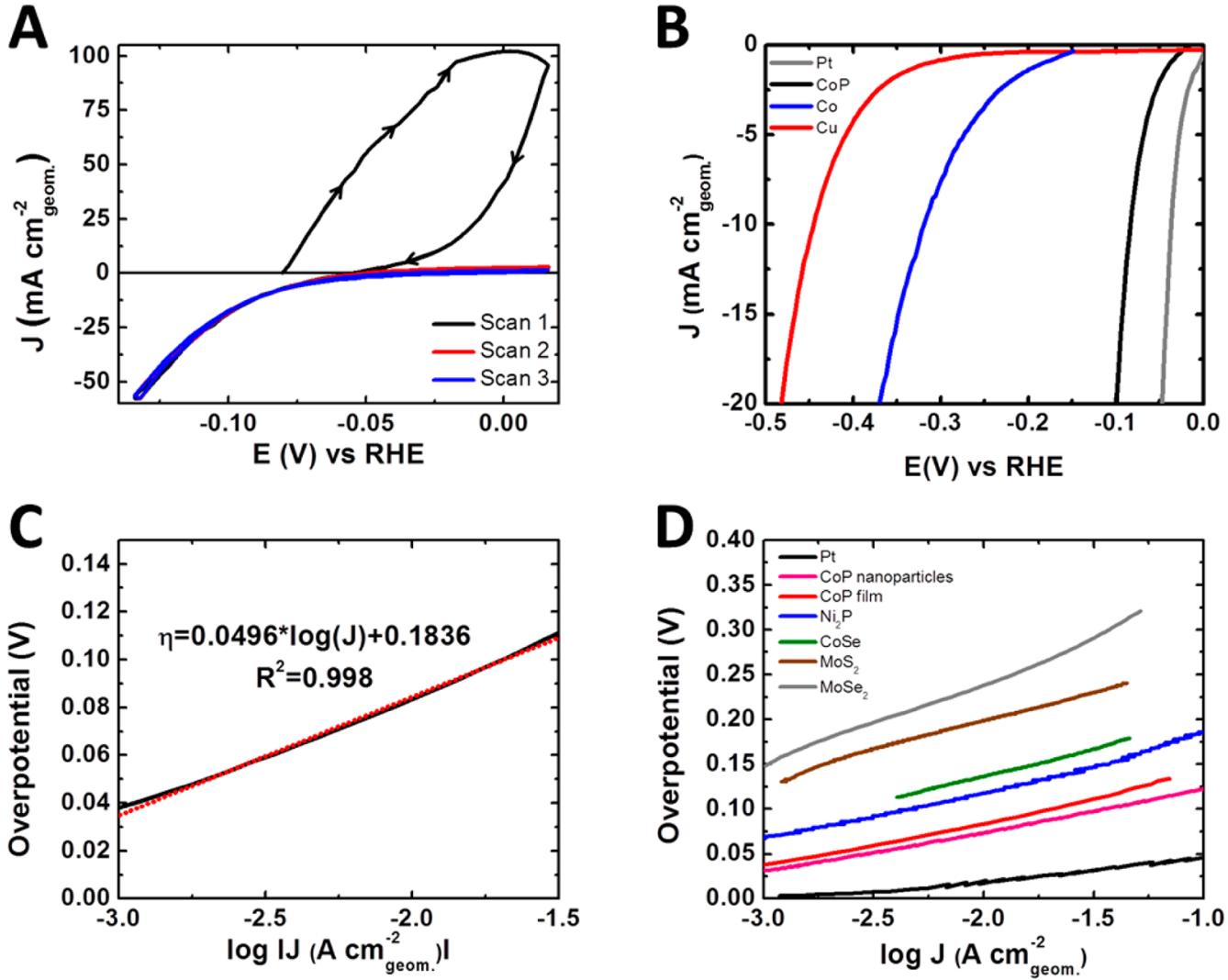

Figure 5. (A) Cyclic voltammetric data for cobalt-phosphide thin films on glassy carbon in aqueous $0.50 \mathrm{M} \mathrm{H}_{2} \mathrm{SO}_{4}$. (B) Current density vs potential data for Pt (gray), the third scan of $\mathrm{CoP}$ (black), $\mathrm{Co}$ (blue), and $\mathrm{Cu}$ (red). (C) Tafel plot of CoP from the current density vs potential data in panel B. (D) Tafel plots that compare the activity of the film in $0.50 \mathrm{M} \mathrm{H}_{2} \mathrm{SO}_{4}$ with that of $\mathrm{Pt}^{21} \mathrm{CoP}$ nanoparticles, ${ }^{21} \mathrm{Ni}_{2} \mathrm{P}$ nanoparticles, ${ }^{20} \mathrm{CoSe}$ thin films, ${ }^{41} \mathrm{MoSe}_{2}$ thin films, ${ }^{42}$ and $\mathrm{MoS}_{2}$ thin films. ${ }^{9}$
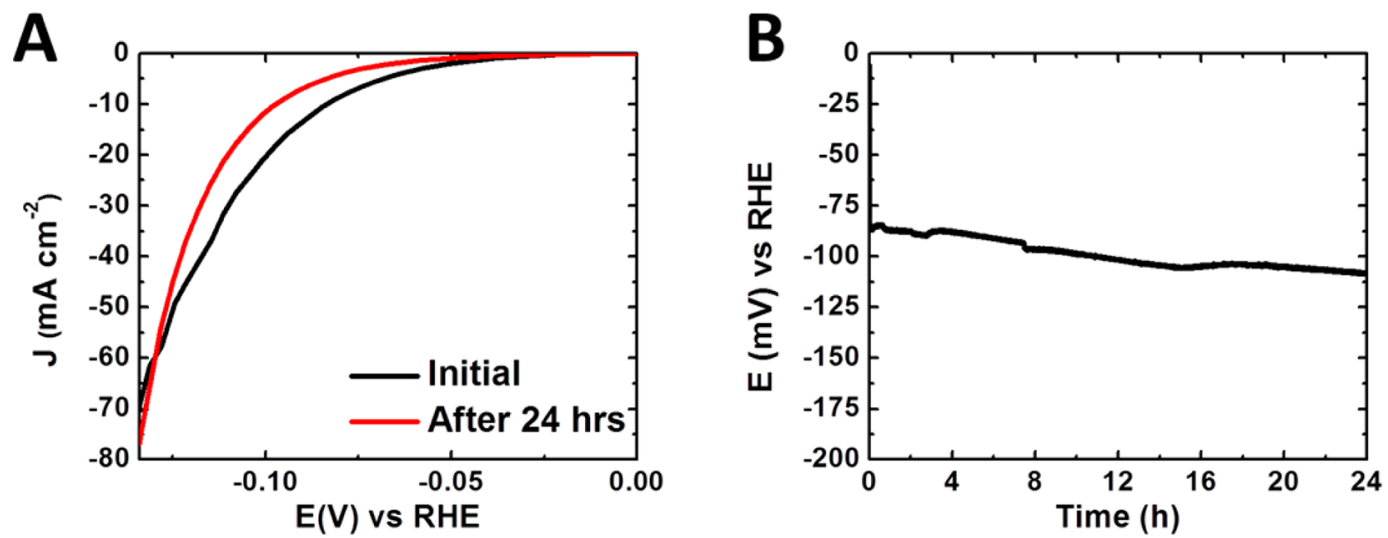

Figure 6. (A) Current density vs potential data in $0.50 \mathrm{M} \mathrm{H}_{2} \mathrm{SO}_{4}$, for the first cycle and after uninterrupted scans over $24 \mathrm{~h}$. (B) Chronopotentiometry in $0.50 \mathrm{M} \mathrm{H}_{2} \mathrm{SO}_{4}$ at a constant current density of $10 \mathrm{~mA} \mathrm{~cm}$.

orthophosphate salts. This behavior may be a consequence of the air-oxidation of the sample when removed from the deposition solution, rinsed with Nanopure water, and transferred to the XPS instrument.

The large anodic current observed in the first voltammetric cycle is consistent with expectations for the quantitative anodic dissolution of metallic cobalt to the divalent cation, $\mathrm{Co}^{2+}$, which is desorbed into solution. Under HER conditions, dissolution of $\mathrm{CoO}$ and $\mathrm{Co}_{2} \mathrm{O}_{3}$ evidently also takes place as indicated by the complete loss of cobalt oxides, as well as by the significant decrease in the Co:P atomic ratio observed in the postcatalysis XPS and EDS data. The magnitude of the orthophosphate XPS peak in the as-prepared sample was substantially diminished after the HER cycles. This decrease was consistent with expectations for the cathodic reduction of interfacial orthophosphate species; when the film was removed from solution, in the absence of applied potential, the reduced products readily reverted to the orthophosphates. Hence, ex situ surface spectroscopy showed nonzero, but substantially diminished, orthophosphate coverage; this is as expected for samples that were briefly exposed to air during sample transfer. The net result is an example of an operando purification, with the deposit changing chemically from a composite of active and inert substances to solely the catalytically functional material. 
For the electrodeposited cobalt phosphide film, spectral results from XPS showed that the binding energy of cobalt was significantly lower than either the $\mathrm{Co}^{2+}$ or $\mathrm{Co}^{3+}$ species. This is to be expected since a previous study on metal monophosphides has revealed the covalent nature of the cobaltphosphorus bond. ${ }^{39}$ The covalently bonded CoP is better represented as $\mathrm{Co}^{\delta+} \mathrm{P}^{\delta-}$, where $\delta+$ and $\delta$ - denote partial, noninteger, charges; consequently, the Co peaks would be closer to those of the zerovalent metal. If the interaction between cobalt and phosphorus were purely ionic, the designation would have been $\left[\mathrm{Co}^{3+}\right]\left[\mathrm{P}^{3-}\right]$, and the Co peak would be that for the $\mathrm{Co}^{3+}$ species.

The $\eta$ necessary to deliver a proton-reduction current density of $10 \mathrm{~mA} \mathrm{~cm}{ }^{-2}$, a catalytic-activity metric that is an order of magnitude higher than in natural photosynthesis, was $85 \mathrm{mV}$ for electrodeposited CoP. In addition, the CoP electrodeposits displayed stability in acidic environments, in that after $24 \mathrm{~h}$ of uninterrupted HER-voltammetric cycles, $\eta$ increased by only $17.5 \pm 4.5 \mathrm{mV}$. The results for the electrodeposited CoP micrometer-sized particles are comparable to those obtained using $\mathrm{CoP}$ nanoparticles. ${ }^{21}$ In terms of $\eta$, the comparative catalytic performance of the CoP film is as follows (Figure 5): $\eta_{\mathrm{Pt}}<\eta_{\mathrm{CoP} \text { film }}=\eta_{\mathrm{CoP} \mathrm{NP}}, \eta_{\mathrm{Ni}_{2} \mathrm{P}}<\eta_{\mathrm{CoSe}_{2}}<\eta_{\mathrm{MoS}_{2}}<\eta_{\mathrm{MoSe}_{2}}$.

\section{CONCLUSION}

Cobalt phosphide was prepared, as a film on a copper substrate, by cathodic deposition from a boric acid solution of $\mathrm{Co}^{2+}$ and $\mathrm{H}_{2} \mathrm{PO}_{2}{ }^{-}$. Surface structural and compositional analysis of the film prior to the electrocatalysis measurements indicated that the film consisted of micrometer-sized spherical clusters located randomly and loosely on a slightly rough surface. The composition of both the clusters and surface consisted of cobalt in the metallic, phosphide, and amorphous-oxide forms $\left(\mathrm{CoO} \cdot \mathrm{Co}_{2} \mathrm{O}_{3}\right)$, and of phosphorus as phosphide and orthophosphate. The higher valent species that originated from air-oxidation were remediated upon HER electrocatalysis in sulfuric acid. The operando film purification yielded a functional electrocatalyst with a Co:P stoichiometric ratio of 1:1. The post-HER surface was densely packed with micrometer-sized mesa-like particles whose tops were flat and smooth. The CoP eletrodeposit showed an overvoltage of 85 $\mathrm{mV}$ at a current density of $10 \mathrm{~mA} \mathrm{~cm} \mathrm{c}^{-2}$ and exhibited operando stability in acidic solution, characterized by an increase in $\eta$ of $18 \mathrm{mV}$ after $24 \mathrm{~h}$ of uninterrupted operation. In terms of $\eta$, the comparative catalytic performance of $\mathrm{CoP}$ is $\eta_{\mathrm{Pt}}<\eta_{\mathrm{CoP} \text { film }} \leq$ $\eta_{\mathrm{CoP} \mathrm{NP}}, \eta_{\mathrm{Ni}_{2} \mathrm{P}}<\eta_{\mathrm{CoSe}_{2}}<\eta_{\mathrm{MoS}_{2}}<\eta_{\mathrm{MoSe}_{2}}$.

\section{ASSOCIATED CONTENT}

\section{S Supporting Information}

Text describing physical characterization methods, figures showing XRD of samples after voltammetry, Faradaic efficiency measurements, fitted XPS spectra, and AFM of samples before and after voltammetry, and tables listing atomic abundances and ratio of phosphorous oxidation states. This material is available free of charge via the Internet at http://pubs.acs.org.

\section{AUTHOR INFORMATION}

\section{Corresponding Authors}

*(M.P.S.) E-mail: m-soriaga@tamu.edu.

*(N.S.L.) E-mail: nslewis@caltech.edu.

\section{Notes}

The authors declare no competing financial interest.

\section{ACKNOWLEDGMENTS}

This material is based upon work performed by the Joint Center for Artificial Photosynthesis, a DOE Energy Innovation Hub, supported through the Office of Science of the U.S. Department of Energy under Award No. DE-SC0004993. A.I.C. acknowledges a National Science Foundation Graduate Research Fellowship for support.

\section{REFERENCES}

(1) Lewis, N. S.; Nocera, D. G. Powering the Planet: Chemical Challenges in Solar Energy Utilization. Proc. Natl. Acad. Sci. U. S. A. 2006, 103, 15729-15735.

(2) Lewis, N. S. Toward Cost-Effective Solar Energy Use. Science 2007, 315, 798-801.

(3) Turner, J.; Sverdrup, G.; Mann, M. K.; Maness, P.-C.; Kroposki, B.; Ghirardi, M.; Evans, R. J.; Blake, D. Renewable Hydrogen Production. Int. J. Energy Res. 2008, 32, 379-407.

(4) Walter, M. G.; Warren, E. L.; McKone, J. R.; Boettcher, S. W.; Mi, Q.; Santori, E. A.; Lewis, N. S. Solar Water Splitting Cells. Chem. Rev. (Washington, DC, U. S.) 2010, 110, 6446-6473.

(5) Gray, H. B. Powering the Planet with Solar Fuel. Nat. Chem. 2009, 1, 7-7.

(6) Merki, D.; Hu, X. Recent Developments of Molybdenum and Tungsten Sulfides as Hydrogen Evolution Catalysts. Energy Environ. Sci. 2011, 4, 3878-3888.

(7) Laursen, A. B.; Kegnæs, S.; Dahl, S.; Chorkendorff, I. Molybdenum Sulfides-Efficient and Viable Materials for Electroand Photoelectrocatalytic Hydrogen Evolution. Energy Environ. Sci. 2012, 5, 5577-5591.

(8) Vrubel, H.; Hu, X. Growth and Activation of an Amorphous Molybdenum Sulfide Hydrogen Evolving Catalyst. ACS Catal. 2013, 2002-2011.

(9) Benck, J. D.; Chen, Z.; Kuritzky, L. Y.; Forman, A. J.; Jaramillo, T. F. Amorphous Molybdenum Sulfide Catalysts for Electrochemical Hydrogen Production: Insights into the Origin of Their Catalytic Activity. ACS Catal. 2012, 2, 1916-1923.

(10) Kibsgaard, J.; Chen, Z.; Reinecke, B. N.; Jaramillo, T. F. Engineering the Surface Structure of $\mathrm{MoS}_{2}$ to Preferentially Expose Active Edge Sites For electrocatalysis. Nat. Mater. 2012, 11, 963-969.

(11) Bonde, J.; Moses, P. G.; Jaramillo, T. F.; Nørskov, J. K.; Chorkendorff, I. Hydrogen Evolution on Nano-Particulate Transition Metal Sulfides. Faraday Discuss. 2009, 140, 219-231.

(12) Kong, D.; Wang, H.; Cha, J. J.; Pasta, M.; Koski, K. J.; Yao, J.; Cui, Y. Synthesis of $\mathrm{MoS}_{2}$ and $\mathrm{MoSe}_{2}$ Films with Vertically Aligned Layers. Nano Lett. 2013, 13, 1341-1347.

(13) Velazquez, J. M.; Saadi, F. H.; Pieterick, A. P.; Spurgeon, J. M.; Soriaga, M. P.; Brunschwig, B. S.; Lewis, N. S. Synthesis and Hydrogen-Evolution Activity of Tungsten Selenide Thin Films Deposited on Tungsten Foils. J. Electroanal. Chem. 2014, 716, 45-48.

(14) Kong, D.; Cha, J. J.; Wang, H.; Lee, H. R.; Cui, Y. First-Row Transition Metal Dichalcogenide Catalysts for Hydrogen Evolution Reaction. Energy Environ. Sci. 2013, 6, 3553-3558.

(15) Chen, W. F.; Wang, C. H.; Sasaki, K.; Marinkovic, N.; Xu, W.; Muckerman, J. T.; Zhu, Y.; Adzic, R. R. Highly Active and Durable Nanostructured Molybdenum Carbide Electrocatalysts for Hydrogen Production. Energy Environ. Sci. 2013, 6, 943-951.

(16) Liu, Q.; Tian, J.; Cui, W.; Jiang, P.; Cheng, N.; Asiri, A. M.; Sun, X. Carbon Nanotubes Decorated with CoP Nanocrystals: A Highly Active Non-Noble-Metal Nanohybrid Electrocatalyst for Hydrogen Evolution. Angew. Chem. 2014, 126 (26), 6828-6832.

(17) Tian, J.; Liu, Q.; Asiri, A. M.; Sun, X. Self-Supported Nanoporous Cobalt Phosphide Nanowire Arrays: An Efficient 3D Hydrogen-Evolving Cathode over the Wide Range of $\mathrm{pH}$ 0-14. J. Am. Chem. Soc. 2014, 136, 7587-7590.

(18) Xiao, P.; Alam Sk, M.; Thia, L.; Ge, X.; Lim, R. J.; Wang, J.-Y.; Lim, K. H.; Wang, X. Molybdenum Phosphide as an Efficient Electrocatalyst for Hydrogen Evolution Reaction. Energy Environ. Sci. 2014, 7, 2624-2629. 
(19) Feng, L.; Vrubel, H.; Bensimon, M.; Hu, X. Easily-Prepared Dinickel Phosphide $\left(\mathrm{Ni}_{2} \mathrm{P}\right)$ Nanoparticles as an Efficient and Robust Electrocatalyst for Hydrogen Evolution. Phys. Chem. Chem. Phys. 2014, 16, 5917-5921.

(20) Popczun, E. J.; McKone, J. R.; Read, C. G.; Biacchi, A. J.; Wiltrout, A. M.; Lewis, N. S.; Schaak, R. E. Nanostructured Nickel Phosphide as an Electrocatalyst for the Hydrogen Evolution Reaction. J. Am. Chem. Soc. 2013, 135, 9267-9270.

(21) Popczun, E. J.; Read, C. G.; Roske, C. W.; Lewis, N. S.; Schaak, R. E. Highly Active Electrocatalysis of the Hydrogen Evolution Reaction by Cobalt Phosphide Nanoparticles. Angew. Chem., Int. Ed. 2014, 53, 5427-5430.

(22) Burchardt, T. The Hydrogen Evolution Reaction on $\mathrm{NiP}_{\mathrm{x}}$ Alloys. Int. J. Hydrogen Energy 2000, 25, 627-634.

(23) Burchardt, T.; Hansen, V.; Våland, T. Microstructure and Catalytic Activity Towards the Hydrogen Evolution Reaction of Electrodeposited $\mathrm{NiP}_{\mathrm{x}}$ Alloys. Electrochim. Acta 2001, 46, 2761-2766.

(24) Paseka, I. Evolution of Hydrogen and Its Sorption on Remarkable Active Amorphous Smooth Ni-P(X) Electrodes. Electrochim. Acta 1995, 40, 1633-1640.

(25) Paseka, I.; Velicka, J. Hydrogen Evolution and Hydrogen Sorption on Amorphous Smooth $\mathrm{Me}-\mathrm{P}(\mathrm{X})(\mathrm{Me}=\mathrm{Ni}, \mathrm{Co}$ and $\mathrm{Fe}-\mathrm{Ni})$ Electrodes. Electrochim. Acta 1997, 42, 237-242.

(26) Morikawa, T.; Nakade, T.; Yokoi, M.; Fukumoto, Y.; Iwakura, C. Electrodeposition of Ni-P Alloys from Ni-Citrate Bath. Electrochim. Acta 1997, 42, 115-118.

(27) Shirley, D. A. High-Resolution X-ray Photoemission Spectrum of the Valence Bands of Gold. Phys. Rev. B 1972, 5, 4709-4714.

(28) Biesinger, M. C.; Payne, B. P.; Grosvenor, A. P.; Lau, L. W. M.; Gerson, A. R.; Smart, R. S. C. Resolving Surface Chemical States in XPS Analysis of First Row Transition Metals, Oxides and Hydroxides: Cr, Mn, Fe, Co and Ni. Appl. Surf. Sci. 2011, 257, 2717-2730.

(29) McIntyre, N. S.; Cook, M. G. X-Ray Photoelectron Studies on Some Oxides and Hydroxides of Cobalt, Nickel, and Copper. Anal. Chem. 1975, 47, 2208-2213.

(30) McIntyre, N. S.; Johnston, D. D.; Coatsworth, L. L.; Davidson, R. D.; Brown, J. R. X-ray Photoelectron Spectroscopic Studies of Thin Film Oxides of Cobalt and Molybdenum. Surf. Interface Anal. 1990, 15, 265-272.

(31) Tan, B. J.; Klabunde, K. J.; Sherwood, P. M. A. XPS Studies of Solvated Metal Atom Dispersed (SMAD) Catalysts. Evidence for Layered Cobalt-Manganese Particles on Alumina and Silica. J. Am. Chem. Soc. 1991, 113, 855-861.

(32) Nemoshalenko, V. V.; Didyk, V. V.; Senekevich, A. I. Russ. J. Org. Chem. 1983, 28, 2182.

(33) Cobo, S.; Heidkamp, J.; Jacques, P.-A.; Fize, J.; Fourmond, V.; Guetaz, L.; Jousselme, B.; Ivanova, V.; Dau, H.; Palacin, S.; Fontecave, M.; Artero, V. A Janus Cobalt-Based Catalytic Material for ElectroSplitting of Water. Nat. Mater. 2012, 11, 802-807.

(34) Okamoto, Y.; Nitta, Y.; Imanaka, T.; Teranishi, S. Surface Characterisation of Nickel Boride and Nickel Phosphide Catalysts by X-ray Photoelectron Spectroscopy. J. Chem. Soc., Faraday Trans. 1 1979, 75, 2027-2039.

(35) Tyczkowski, J.; Kapica, R.; Łojewska, J. Thin Cobalt Oxide Films for Catalysis Deposited by Plasma-Enhanced Metal-Organic Chemical Vapor Deposition. Thin Solid Films 2007, 515, 6590-6595.

(36) Hadjiev, V. G.; Iliev, M. N.; Vergilov, I. V. The Raman Spectra of $\mathrm{Co}_{3} \mathrm{O}_{4}$. J. Phys. C: Solid State Phys. 1988, 21, No. L199.

(37) Frost, R. L. An Infrared and Raman Spectroscopic Study of Natural Zinc Phosphates. Spectrochim. Acta, Part A 2004, 60, 14391445 .

(38) Mitchell, P. C. H.; Parker, S. F.; Simkiss, J.; Simmons, J.; Taylor, M. G. Hydrated Sites in Biogenic Amorphous Calcium Phosphates: An Infrared, Raman, and Inelastic Neutron Scattering Study. J. Inorg. Biochem. 1996, 62, 183-197.

(39) Grosvenor, A. P.; Wik, S. D.; Cavell, R. G.; Mar, A. Examination of the Bonding in Binary Transition-Metal Monophosphides MP ( $\mathrm{M}=$ $\mathrm{Cr}, \mathrm{Mn}, \mathrm{Fe}, \mathrm{Co}$ ) by X-ray Photoelectron Spectroscopy. Inorg. Chem. 2005, 44, 8988-8998.
(40) Plambeck, J. A.; Bard, A. J.; Henning, L. Encyclopedia of Electrochemistry of the Elements, Vol. 3; Taylor \& Francis Group: Abington, Oxon, United Kingdom, 1973.

(41) Carim, A. I.; Saadi, F. H.; Soriaga, M. P.; Lewis, N. S. Electrocatalysis of the Hydrogen-Evolution Reaction by Electrodeposited Amorphous Cobalt Selenide Films. J. Mater. Chem. A 2014, $2,13835-13839$.

(42) Saadi, F. H.; Carim, A. I.; Velazquez, J. M.; Baricuatro, J. H.; McCrory, C. C. L.; Soriaga, M. P.; Lewis, N. S. Operando Synthesis of Macroporous Molybdenum Diselenide Films for Electrocatalysis of the Hydrogen-Evolution Reaction. ACS Catal. 2014, 2866-2873. 